\title{
Efeito da umidade inicial e do tempo de cura nas propriedades mecânicas de misturas solo-cimento
}

\author{
Kendi Sanbonsuge ${ }^{1}$, Kamilla Vasconcelos ${ }^{2}$, Liedi Bernucci ${ }^{3}$, Edson de Moura ${ }^{4}$ \\ 1ARCADIS,kendisanbonsuge@bol.com.br \\ 2Escola Politécnica da Universidade de São Paulo, USP, kamilla.vasconcelos@gmail.com \\ ${ }^{3}$ Escola Politécnica da Universidade de São Paulo, USP,liedi@usp.br \\ ${ }^{4}$ Escola Politécnica da Universidade de São Paulo, USP, edmoura@usp.br
}

\section{Recebido:}

29 de setembro de 2016

Aceito para publicação:

17 de agosto de 2017

Publicado:

30 de dezembro de 2017

Editor de área:

Jorge Barbosa Soares

Palavras-chaves:

Solo-cimento,

Pavimentação,

Umidade inicial de moldagem,

Tempo de cura,

Retroanálise.

\section{Keywords:}

Soil-cement,

Initial moisture compaction,

Curing time,

Backcalculation.

DOI:10.14295/transportes.v25i4.1257

\begin{abstract}
RESUMO
Misturas de solo-cimento são muitas vezes empregadas como material de base ou subbase para pavimentação em locais com pouca disponibilidade de agregados. $O$ processo de dosagem comumente empregado no Brasil consiste na verificação de um valor de resistência à compressão simples mínima aos 7 dias de cura. 0 procedimento convencional de mistura em laboratório consiste em incorporar cimento ao solo na umidade higroscópica e, posteriormente, a água para compactação. Comparou-se este procedimento com a técnica que simula a condição de construção que consiste na mistura do cimento ao solo na umidade de coleta na jazida. Foram compactados corpos de prova por impacto e realizados ensaios de Módulo de Resiliência (MR), Resistência à Compressão Simples (RCS) e Resistência à Tração por Compressão Diametral (RTCD) para quatro tempos de cura (7, 14, 21 e 28 dias). Os resultados apontaram a influência da umidade inicial de mistura nos parâmetros volumétricos e mecânicos das misturas de solo-cimento. As deflexões de um trecho experimental com base de solo-cimento também foram avaliadas para comparação do módulo de resiliência obtido por retroanálise com os dados obtidos em laboratório. Os valores de módulo de resiliência da camada de solocimento em campo são inferiores comparados aos dados obtidos em laboratório, podendo ter sido ocasionado por início do processo de microfissuração da base cimentada, além de fatores executivos. Pode-se ainda somar a esse fator, a forma como a umidade é ajustada em laboratório e em campo.
\end{abstract}

\section{ABSTRACT}

The soil-cement is commonly used as a base course material for pavements, especiallywhere there are limited sources of coarse aggregates. In the mixture design process, it is verified the minimum value of compressive strength after 7 days of curing. The standard mixture procedure is to incorporate the cement to the soil at the hygroscopic humidity. In this study, another mixing process was also investigated, where the soil humidity was kept the same as collected, in order to simulate the mixing procedure in the field. The evaluation was done through the impact compaction, and also mechanical tests, as, triaxial resilient modulus (RM), compressive strength, and indirect tensile strength, for four curing times $(7,14,21$ e 28 days). The results have shown the influence of the initial mixing humidity in the volumetric and mechanical parameters of the soilcement mixtures. The experimental test site data were compared to the laboratory ones through backcalculation, and the RM from the field data were smaller that the RM from the laboratory, probably due to the initiation of microcracking phenomenon and constructive issues. Also, one may add the differences in the way the humidity is adjusted in the field and in the laboratory.
\end{abstract}

\section{INTRODUÇÃO}

O solo-cimento é uma mistura em determinadas proporções de solo, cimento e água. A proporção de cimento ao solo depende do comportamento desejado: (i) material menos sensível à expansão por presença de água, designado por solo melhorado por cimento, ou (ii) conjugado a esse comportamento, uma 
alta rigidez, denominado por solo-cimento.

Para Balbo (2007), a diferença entre o solo melhorado por cimento e o solo-cimento reside não somente na quantidade de cimento empregado, mas também na resposta mecânica do material de sua resistência à tração na flexão. 0 solo melhorado por cimento tem como função dar estabilidade ao solo, diminuindo sua expansão e plasticidade, resultando em um material estável, mas de baixa rigidez quando comparado com o solo-cimento. No caso de solo melhorado por cimento, geralmente são empregados teores de 2 a 4\% de cimento em massa na sua dosagem (DNIT, 2006; AUST STAB, 2012).

No estado de São Paulo, até meados de 1990, a base de solo-cimento chegou a ocupar cerca de 30\% da malha rodoviária gerenciada pelo DER-SP (Nogamiet al., 1990). Seu desempenho depende de fatores construtivos como temperatura ambiente, umidade relativa do ar, tempo e técnica de cura e duração entre mistura e compactação (Guthrieet al., 2009). A mineralogia e microestrutura do solo, além de sua granulometria, são características definidoras da reação do cimento com o solo. Parente et al. (2002) avaliaram o comportamento do solo-cimento com dois solos tropicais, sendo um laterítico e outro não laterítico (porém de mesma classificação AASHTO e USCS) e concluíram que a mistura composta com o solo de comportamento laterítico apresentou melhor desempenho que a mistura composta com solo de comportamento não laterítico, independente do tempo de cura e do teor de cimento. Isto, em geral, ocorre pois os solos lateríticos são estáveis por natureza e o cimento age como aditivo de aumento de resistência, que já é geralmente de média a elevada.

\section{SOLO-CIMENTO}

O desempenho do solo-cimento em sua etapa construtiva pode ser afetado por fatores como a umidade inicial do solo, tempo entre a mistura e a compactação, umidade relativa do ar, incidência de ventos e temperatura, e o tempo de cura (após a compactação). A seguir, são apresentados os fatores que serviram como referência para o desenvolvimento desta pesquisa.

\subsection{Efeito do tempo de cura}

O aumento da rigidez de misturas de solo-cimento com o tempo de cura está associado aos componentes presentes no cimento, bem como aos compostos gerados durante o processo de hidratação. Compostos como o silicato tricálcico $\left(\mathrm{SiO}_{2} 3 \mathrm{CaO}\right)$ geram altos ganhos de resistência em curtos períodos de cura. Por outro lado, compostos como o silicato dicálcico $\left(\mathrm{SiO}_{2} 2 \mathrm{CaO}\right)$ resultam em maiores ganhos em períodos mais longos de cura (Balbo, 2007). Segundo Almeida (2009), a reação dos compostos do cimento é uma função de sua hidratação pela água presente no solo, e pode ser representada conforme mostram as Equações (1) e (2).

$$
\begin{aligned}
& \mathrm{SiO}_{2} 30 \mathrm{Ca}+\mathrm{H}_{2} \mathrm{O}=\mathrm{Si} \mathrm{H} \mathrm{H}_{2} \mathrm{O} 2 \mathrm{OC}+\mathrm{CaO} \\
& \mathrm{SiO}_{2} 2 \mathrm{OCa}+\mathrm{H}_{2} \mathrm{O}=\mathrm{Si} \mathrm{H} \mathrm{H}_{2} \mathrm{OCa}+\mathrm{CaO}
\end{aligned}
$$

Após a reação do cimento com a água, é liberado um gel de silicato bi e monocálcico, mais uma parcela de cal livre. Bechara et al. (2010) verificaram por meio de ensaios de Módulo de Resiliência (MR) e de Resistência à Compressão Simples (RCS), em dois solos de granulometria semelhantes, mas de classificação pedológica distinta, sendo um arenoso laterítico (LA') e outro arenoso não-laterítico (NA'), que cerca de $50 \%$ da resistência final do solo-cimento ocorre nos primeiros 3 dias de cura, sendo o solo de classificação não-laterítico com maior influência da ação cimentante.

Pinillaet al. (2011), em um estudo com solos tratados com cinza volante e cinza de alto forno, verificaram que a maior parcela do aumento da rigidez ocorre entre o $7^{\circ}$ e o $14^{\circ}$ dia de cura, seguido de um curto aumento de resistência até completar os 28 dias de cura. Moh (1965) apud Vendruscolo (1996) divide as reações do solo-cimento em (i) primária, onde ocorre a hidratação e hidrólise formando cal, e (ii) secundária, onde são formadas as substâncias cimentíceas sobre a superfície do solo, causando a floculação dos grãos de argila cimentados nos pontos de contato.

Mitchell e El Jack (1966) mostraram, por meio de ensaios com microscópio eletrônico de varredura em três solos distintos (sendo um formado por $100 \%$ de argila), que a mistura de solo e cimento muda 
da condição de partículas dispersas para uma condição de massa homogênea, ao longo do processo de hidratação, de forma que, após longos períodos de cura, já não é mais possível diferenciar os componentes da mistura.

\subsection{Efeito da Umidade de Moldagem}

Nos solos, a variação da umidade afeta substancialmente sua resistência, principalmente no ramo úmido da curva de compactação. A quantidade de água presente no solo no momento de sua compactação afeta seu peso específico aparente seco ( $\gamma$ s), índice de vazios (e) e grau de saturação ( $\mathrm{S} \%$ ), além de alterar sua microestrutura. Depois de compactado, a variação da umidade, seja por ganho, como por perda, também exerce influência no comportamento mecânico do solo. Sabe-se que os solos que possuem menor sensibilidade à ação da umidade são os lateríticos que depois de compactados permitem a perda água, mas não a reabsorvem totalmente. Isso se deve à mineralogia e estrutura dos minerais presentes no solo agirem como hidrofugantes (Nogami e Villibor, 1995; Luz e Parreira, 2003). Esse comportamento é denominado como irreversibilidade parcial de propriedades, ou seja, o solo não retorna à mesma consistência após a reabsorção da água.

A secagem prévia do solo pode interferir nos valores de peso específico seco máximo e no teor de umidade ótima. Para Nogami e Villibor (1995), a secagem prévia em alguns solos lateríticos pode modificar irreversivelmente as propriedades da fração argilosa. Os autores destacam ainda que essa peculiaridade se manifesta de forma acentuada em lateritashidromorfas (plintitas) que podem enrijecer de forma irreversível. Massad (2003) menciona um caso de solo de barragem, em que foi verificada uma diferença de $4 \%$ a menos entre a umidade ótima do ensaio de Proctor e a compactação realizada com o solo na umidade de campo devido aos processos diferentes estabelecidos em laboratório e em campo. Para Pinto (2006), o efeito da pré-secagem em alguns solos pode ser considerável, aumentando seu peso específico aparente seco e o teor de umidade ótima no caso de solos argilosos de decomposição de gnaisse e no caso de solos areno-argilosos lateríticos, resultando em umidades ótimas menores, com pouca influência no peso específico. A norma de compactação de solos da ABNT (1986) prevê a realização do ensaio com o material preparado em torno de 5\% abaixo da umidade ótima presumível, evitando assim a secagem total (até a umidade higroscópica).

O solo, por ser o componente em maior proporção em misturas de solo-cimento, atribui suas características à mistura. Com a adição do cimento, o fator água/cimento também terá grande influência na resistência desse tipo de mistura. Esses fenômenos foram estudados por Yoon e Farsakh (2008) para um solo classificado como A-2 na classificação AASHTO misturado com teores de $8 \%, 10 \%$ e $12 \%$ de cimento. Foi verificado que a partir de uma determinada umidade, a adição de água reduz de forma acentuada sua resistência à compressão simples.

\section{MATERIAIS E PROCEDIMENTOS DOS ENSAIOS}

Para esse estudo foi coletada uma amostra de solo proveniente da PTP-10, denominada "Estrada do Leite", uma rodovia de baixo volume de tráfego de pista simples que interliga os municípios de Patrocínio Paulista a Batatais, no interior do Estado de São Paulo, e cimento tipo CP II-E 32. Para manter a umidade natural do solo, a amostra coletada foi mantida em saco plástico vedado até a realização dos ensaios em laboratório.

\subsection{Caracterização dos materiais (solo e cimento)}

Foram realizados ensaios dos índices de consistência (limites de Atterberg) e granulometria para classificar o solo pelo sistema AASHTO (American Association of State Highway and Transportation Officials) e ensaios de compactação pela metodologia MCT (Miniatura, Compactado, Tropical) aplicada a solos tropicais. 0 solo foi classificado como A-2-4 (AASHTO) e LA' (MCT). Na Tabela 1, é apresentado um resumo dos resultados obtidos. Um resumo das características físicas e químicas do cimento CP II-E 32 empregado neste estudo é apresentado na Tabela 2. 
Tabela 1: Resumo das características do solo

\begin{tabular}{ll}
\hline Ensaios & Resultados \\
\hline LL (\%) & 17,3 \\
LP (\%) & 16,0 \\
IP (\%) & 1,3 \\
Peso específico dos grãos $\left(\mathrm{g} / \mathrm{cm}^{3}\right)$ & 2,703 \\
Esfericidade Média & 0,90 \\
Passante \# 2,00mm (\%) & 100,00 \\
Passante \# 0,42mm (\%) & 99,5 \\
Passante 75 $\mu \mathrm{m}(\%)$ & 29,5 \\
c' $^{\prime}$ & 0,75 \\
d' $^{\prime}$ & 30,15 \\
e' & 0,61 \\
PI (\%) & 117 \\
Classificação AASHTO & $\mathrm{A}-2-4$ \\
Classificação MCT & LA' \\
\hline
\end{tabular}

Tabela 2: Propriedades físicas e químicas do cimento fornecidas pelo fabricante

\begin{tabular}{lllll}
\hline Características & Caracterização & Normas & Referência Normativa & Resultados \\
\hline \multirow{4}{*}{ Químicas } & Perda ao fogo (\%) & NBR 5743 & $<6,5$ & 5,08 \\
& MgO & NBR 5742 & $<6,5$ & 5,23 \\
& SO3 & NBR 5745 & $<4,0$ & 1,91 \\
& CO2 & NBR 11583 & $<5,0$ & 4,16 \\
& RI & NBR 5744 & $<2,5$ & 1,74 \\
\hline \multirow{5}{*}{ Físicas } & Finura \# 0,075mm (\%) & NBR 11579 & $<12,0$ & 1,3 \\
& Blaine (cm²/g) & NBR 7224 & $>2.600$ & 4.092 \\
& Tempo de pega- inicio (h) & NBR 11581 & $>1$ & $3: 26$ \\
& Tempo de pega - fim (h) & $<10$ & $4: 46$ \\
\multirow{2}{*}{ Mecânicas } & RCS 3 dias cura (MPa) & & $>10$ & 20,0 \\
& RCS 7 dias cura (MPa) & NBR 7215 & $>20$ & 26,9 \\
& RCS 28 dias cura (MPa) & & $>32$ & 36,0 \\
\hline
\end{tabular}

\subsection{Dosagem da Mistura Solo-Cimento (Proctor)}

A dosagem foi realizada de acordo com a ABNT (2012a). Foram adotados três percentuais de cimento calculados em relação à massa seca de solo, 2, 5 e 7\%. Verificou-se que o emprego de aproximadamente $4 \%$ de cimento seria suficiente para atingir a resistência mínima normativa de 2,1 MPa aos 7 dias nos ensaios de RCS, conforme apresentado na Figura 1. Visando uma maior segurança de teores praticados em campo, foi adotado o teor de 5\% para o material a ser executado em campo e para as amostras ensaiadas nos demais procedimentos de laboratório apresentados a seguir.

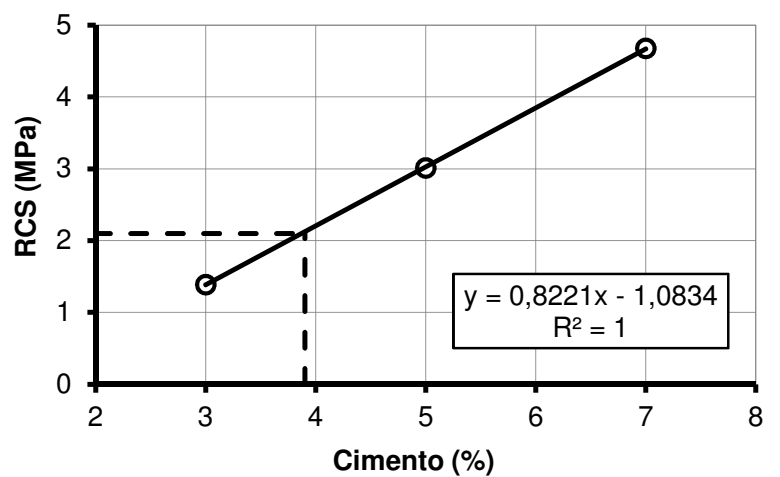

Figura 1. Curva de RCS $\times$ percentual em peso de cimento para 7 dias de cura

Para obtenção da curva de compactação, foi utilizada a energia normal, como empregado em várias pesquisas para melhor comparar as diferenças entre propriedades nos diversos ensaios, embora em campo a energia empregada seja a intermediária, ou mesmo a modificada em alguns casos. As amostras 
foram compactadas em três camadas de igual espessura, sendo cada uma delas compactadas por 25 golpes com o soquete de $2,5 \mathrm{~kg}$ e altura de queda de $30,5 \mathrm{~cm}$ em um cilindro de $1000 \mathrm{~cm}^{3}$, conforme preconizam as especificações para solo ASTM (2012) e ABNT (1986) e, para a mistura de solo-cimento ASTM (2011) e ABNT (2012b).

As misturas de solo-cimento seguiram duas formas distintas de preparação com relação à umidade inicial do solo:

(i) Umidade Higroscópica (UH): o cimento foi adicionado na amostra de solo na umidade higroscópica, conforme ABNT (2012b). Após a mistura e homogeneização, adicionou-se água até o teor ótimo de moldagem. Essa situação representa a condição de mistura em laboratório.

(ii) Umidade de Campo (UC): o cimento foi adicionado à amostra de solo na condição de extração da jazida, conservando sua umidade natural, com valores da ordem de $9 \%$. Após a adição de cimento, adicionou-se água, quando necessário. Essa situação teve como objetivo uma melhor aproximação do procedimento de execução da mistura de solo-cimento realizado em obra.

Na Figura 2 são apresentados os valores obtidos de peso específico seco e teor de umidade para o solo e para o solo-cimento, quando adotada umidade higroscópica (UH) e umidade de campo (UC).

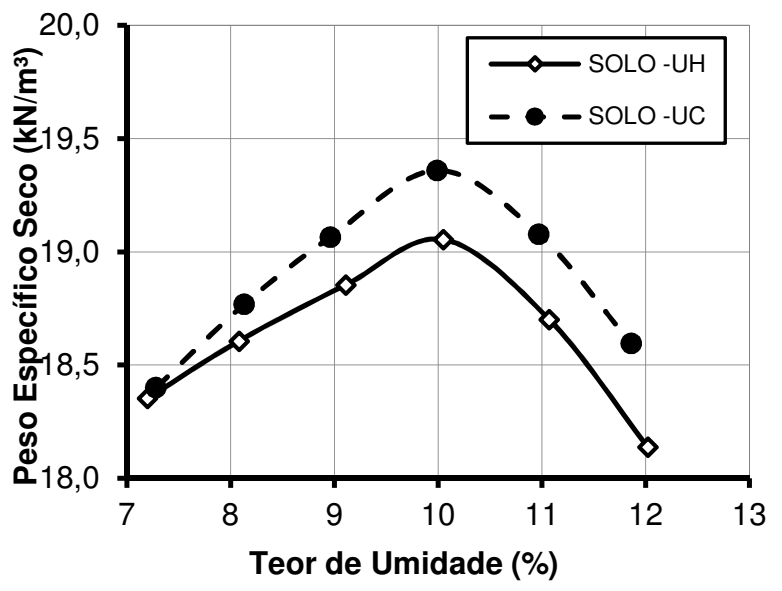

(a)

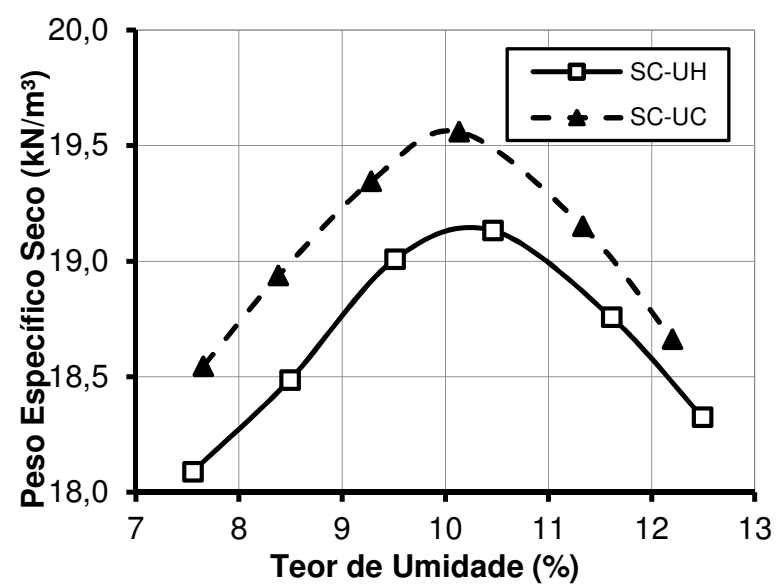

(b)

Figura 2: Curvas de compactação nas duas condições de mistura (UH - umidade higroscópica e UC - umidade natural de campo) para: (a) solo e (b) solo-cimento

Tanto para as amostras de solo, como para as amostras de solo-cimento, houve um aumento no peso específico aparente seco máximo na condição UC. As variações verificadas quando comparados solo e solo-cimento (nas mesmas condições de umidade) consistiram: (i) no aumento do peso específico aparente seco do solo-cimento com relação aos resultados do solo e (ii) em um pequeno aumento no teor de umidade ótima. $\mathrm{O}$ aumento de umidade ótima se deve à grande superfície específica do cimento, resultante da sua finura. 0 aumento de peso específico do solo-cimento em relação ao solo é devido ao melhor entrosamento de grãos, ou seja, ao melhor empacotamento.

\section{METODOLOGIA DE ENSAIOS E RESULTADOS}

Para avaliação da mistura de solo-cimento, foram realizados ensaios de compactação (Proctor), resistência (compressão simples e tração por compressão diametral), rigidez (módulo de resiliência triaxial) e potencial de fissuramento (contração diametral), relatados nos itens que se seguem.

\subsection{Compactação dos corpos de prova para os ensaios de MR, RCS e RTCD}

A partir dos valores obtidos de peso específico seco máximo ( $\gamma$ smax) e teor de umidade ótima (hot) da 
curva de compactação para a amostra de solo-cimento, foram compactados corpos de prova para os ensaios de Resistência à Compressão Simples (RCS), Resistência à Tração por Compressão Diametral (RTCD) e Módulo de Resiliência (MR), sendo utilizados 3 corpos de prova para cada variável (condição de moldagem, UH e UC, e tempo de cura, 3, 7, 14 e 28 dias). A compactação foi realizada em cinco camadas de igual espessura, medidas durante o ensaio com auxílio de uma régua metálica. 0 procedimento não é igual ao ensaio de compactação, pois a altura do corpo de prova para estes ensaios é distinta e obedece a relação mínima de altura de 2 vezes o diâmetro. Cada camada recebeu a aplicação de 24 golpes com o soquete de $2,5 \mathrm{~kg}$ e uma altura de queda de $30,5 \mathrm{~cm}$. Foi utilizado molde cilíndrico tripartido, com diâmetro interno de $10 \mathrm{~cm}$ e altura de $20 \mathrm{~cm}$. Antes da compactação, foram retiradas três amostras da mistura úmida de solo-cimento para determinação da umidade de moldagem.

Após a compactação, as amostras foram extraídas e pesadas para determinação do peso úmido e obtenção do grau de compactação (GC). As amostras apresentaram um GC médio de 100,4\% com um coeficiente de variação de $0,50 \%$. Os ensaios mecânicos acima mencionados foram realizados para as idades de 3, 7, 14 e 28 dias de cura, com o solo-cimento confeccionado nas duas condições de mistura: (i) solo na umidade higroscópica (UH), e (ii) solo na umidade de campo (UC). A cura foi realizada em câmara úmida com temperatura controlada em $25^{\circ} \mathrm{C}$. Foram compactadas 6 amostras (3 para o ensaio de MR e, posteriormente, RCS; e 3 para o ensaio de RTCD) para cada idade de cura e teor de umidade inicial de mistura do solo-cimento, resultando em um total 48 corpos de prova.

\subsection{Resistência à Compressão Simples (RCS)}

Os ensaios foram realizados conforme ABNT (2012c) e ASTM (2007). As amostras foram carregadas axialmente a uma taxa de deslocamento de $1 \mathrm{~mm} / \mathrm{min}$, utilizando uma prensa hidráulica (MTS 810 " $M a$ terial Test System"), até 5\% da força máxima registrada no instante da ruptura. Os resultados de RCS para as duas umidades de moldagem e os quatro tempos de cura são apresentados na Figura 3.

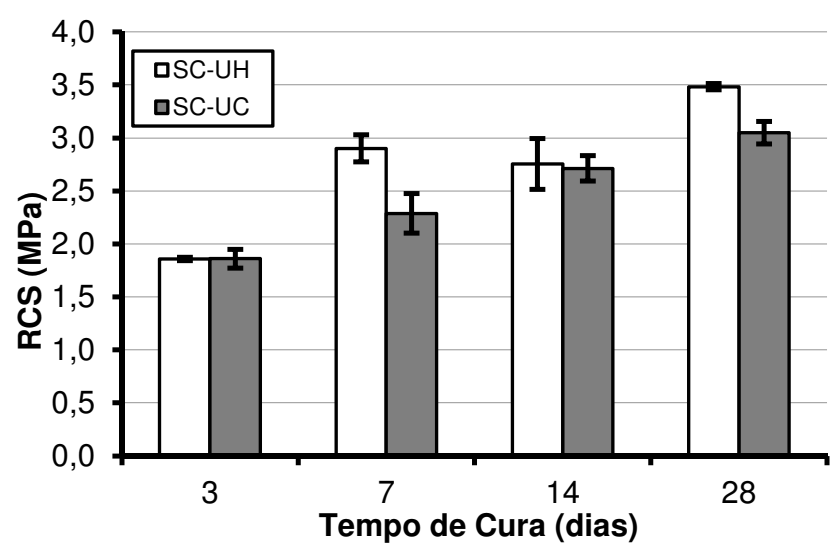

Figura 3: Resistência à compressão simples para alguns períodos de cura nas duas condições de mistura (UH e UC) com $5 \%$ em peso de cimento na mistura

\subsection{Resistência à Tração por Compressão Diametral (RTCD)}

Os ensaios foram parametrizados e calculados conforme ABNT (2011). Como não há norma para testes de RTCD em amostras de solo-cimento, foi empregado o mesmo critério de velocidade normatizado para o ensaio de RCS. As amostras foram carregadas na geratriz do corpo de prova, diametralmente, a uma velocidade de $1 \mathrm{~mm} / \mathrm{min}$, utilizando uma prensa hidráulica (MTS 810 "Material Test System") até 5\% da força máxima registrada no instante da ruptura. Osresultadosobtidosencontram-se ilustradosna Fi-gura 4. 


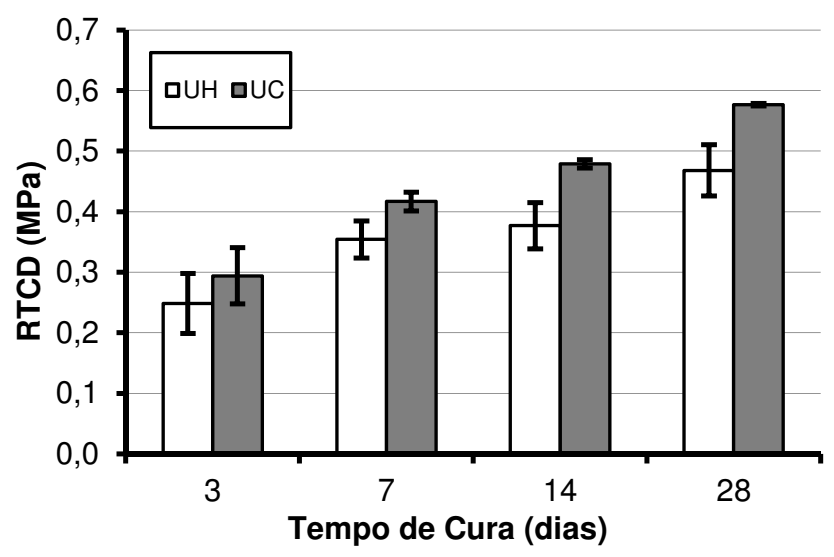

Figura 4: Resistência à tração por compressão diametral para diferentes dias de cura nas duas condições de mistura UH e UC

\subsection{Módulo de Resiliência (MR)}

As amostras foram ensaiadas conforme DNIT (2010). Para uma melhor distribuição das tensões desviadoras aplicadas $(\sigma \mathrm{d})$, os corpos de prova foram capeados com gesso ortodôntico com RCS de $45 \mathrm{MPa}$ após secagem e retração inferior a $0,5 \%$. Os valores de deformação foram coletados para cada tensão desviadora aplicada, em cada combinação de tensão confinante $(\sigma 3)$.

Tabela 3: Valores médios de MR (para relações de $\sigma 3 / \sigma d=2,3$ e 4) nos quatro tempos de cura e duas condições de mistura (UH e UC)

\begin{tabular}{|c|c|c|c|c|c|}
\hline \multirow[b]{2}{*}{ Tempo de Cura (dias) } & \multirow{2}{*}{$\begin{array}{c}\sigma 3 \\
(\mathrm{MPa})\end{array}$} & \multicolumn{2}{|c|}{ UC } & \multicolumn{2}{|c|}{ UH } \\
\hline & & $\begin{array}{l}\text { Média } \\
\text { (MPa) }\end{array}$ & CV (\%) & $\begin{array}{l}\text { Média } \\
\text { (MPa) }\end{array}$ & CV (\%) \\
\hline \multirow{6}{*}{3} & 0,021 & 3.937 & 4,4 & 4.298 & 11,2 \\
\hline & 0,035 & 3.998 & 2,7 & 4.426 & 7,7 \\
\hline & 0,050 & 4.045 & 1,7 & 4.528 & 6,3 \\
\hline & 0,069 & 4.084 & 1,3 & 4.617 & 6,8 \\
\hline & 0,103 & 4.135 & 2,0 & 4.739 & 9,2 \\
\hline & 0,138 & 4.173 & 2,9 & 4.833 & 11,6 \\
\hline \multirow{6}{*}{7} & 0,021 & 5.277 & 7,2 & 6.192 & 6,8 \\
\hline & 0,035 & 5.390 & 7,0 & 6.313 & 5,9 \\
\hline & 0,050 & 5.475 & 6,9 & 6.404 & 5,2 \\
\hline & 0,069 & 5.546 & 6,8 & 6.481 & 4,7 \\
\hline & 0,103 & 5.639 & 6,9 & 6.580 & 3,9 \\
\hline & 0,138 & 5.708 & 6,9 & 6.654 & 3,4 \\
\hline \multirow{6}{*}{14} & 0,021 & 5.732 & 4,6 & 6.462 & 7,1 \\
\hline & 0,035 & 5.864 & 4,6 & 6.617 & 5,5 \\
\hline & 0,050 & 5.965 & 4,6 & 6.734 & 4,2 \\
\hline & 0,069 & 6.049 & 4,6 & 6.833 & 3,2 \\
\hline & 0,103 & 6.158 & 4,6 & 6.963 & 1,9 \\
\hline & 0,138 & 6.240 & 4,6 & 7.060 & 1,0 \\
\hline \multirow{6}{*}{28} & 0,021 & 6.642 & 10,8 & 7.262 & 5,5 \\
\hline & 0,035 & 6.757 & 9,4 & 7.405 & 5,0 \\
\hline & 0,050 & 6.844 & 8,3 & 7.513 & 4,7 \\
\hline & 0,069 & 6.917 & 7,5 & 7.603 & 4,4 \\
\hline & 0,103 & 7.013 & 6,4 & 7.720 & 4,0 \\
\hline & 0,138 & 7.083 & 5,6 & 7.807 & 3,8 \\
\hline
\end{tabular}

A deformação específica $(\varepsilon)$ é calculada por meio da razão entre o deslocamento registrado no momento da aplicação da tensão desviadora $(\sigma \mathrm{d})$ pela altura do corpo de prova. Os resultados obtidos para 
as diversas condições de ensaios encontram-se resumidos na Tabela 3 e Figura 5.0 material não se mostrou sensível à tensão desviadora. Embora também pouco sensível à variação da tensão de confinamento, dada à quantidade de cimento inferior à necessária para tornar a mistura com módulo independente do confinamento, foi adotado o modelo em função da tensão de confinamento.Os coeficientes K1 e K2, bem como o coeficiente de determinação $\left(\mathrm{R}^{2}\right)$ são apresentados na Tabela 4.

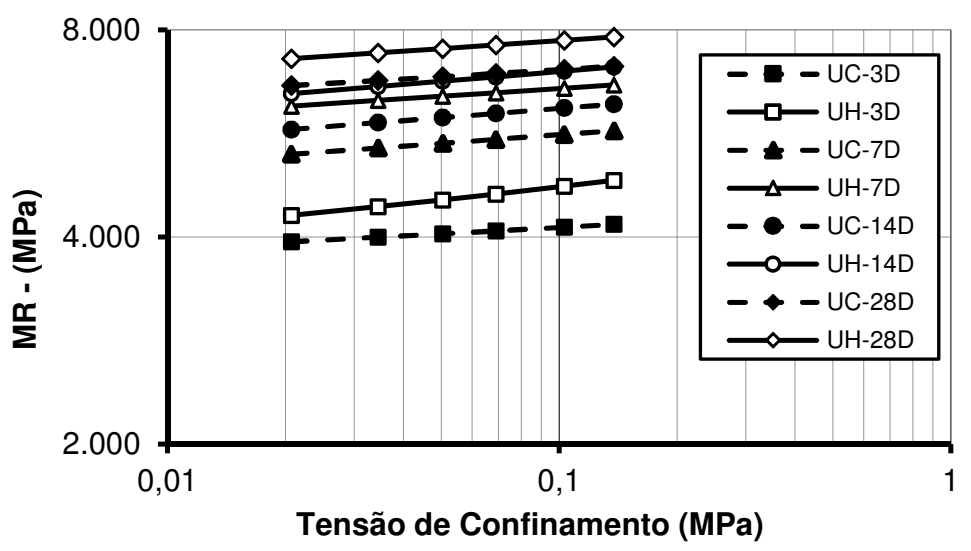

Figura 5: Módulo de resiliência em função da tensão de confinamento para 4 períodos de cura, duas condições de mistura (UH e UC) da mistura de solo com $5 \%$ em peso de cimento.

Tabela 4: Coeficientes do modelo de regressão em função da tensão de confinamento para os quatro períodos de cura e duas condições de mistura (UH e UC)

\begin{tabular}{ccccc}
\hline Tempo de cura & Condição de Moldagem & K1 & K2 & $\mathbf{R}^{\mathbf{2}}$ \\
\hline 3 & UC & 4433,4 & 0,0307 & 0,9999 \\
3 & UH & 5455,4 & 0,0619 & 0,9990 \\
7 & UC & 6196,0 & 0,0414 & 1,0000 \\
7 & UH & 7173,7 & 0,0380 & 1,0000 \\
14 & UC & 6818,3 & 0,0448 & 1,0000 \\
14 & UH & 7742,4 & 0,0467 & 1,0000 \\
28 & UC & 7574,1 & 0,0339 & 1,0000 \\
28 & UH & 8418,8 & 0,0381 & 1,0000 \\
\hline
\end{tabular}

\subsection{Efeito da umidade de mistura (UH e UC) na contração do solo e do SC (solo-cimento)}

Foi realizada a análise da contração axial do solo e retração axial do solo-cimento. As amostras foram moldadas e ensaiadas conforme metodologia MCT, proposta por Nogami e Villibor (1995). Existem outras formas de determinar a contração em solos como o apresentado pela DNER ME 087/94, que emprega o mercúrio na determinação, sendo um ensaio de difícil realização, além dos riscos ambientais e a saúde. 0 ensaio de contração axial pela metodologia MCT permite o monitoramento do progresso da contração, e foi elaborado para aplicação em solos tropicais. 0 método consiste na moldagem de corpos de prova em equipamento Miniatura (MCT) na umidade e peso específico aparente seco esperado de aplicação do material. Após a moldagem, as amostras são medidas com paquímetro, montadas em suporte apropriado, instrumentadas axialmente com um extensômetro e deixadas em local adequado e exposto ao ambiente para perda de água. As medidas de contração foram efetuadas em intervalos regulares de 12 horas até a estabilização da amostra, detectado por leituras sucessivas com valores repetidos. A contração depende principalmente da plasticidade do solo, e quando elevada, pode gerar fissuras prematuras na camada do pavimento. A Figura 6(a) ilustra os corpos de prova durante a realização do ensaio e a Figura 6(b) apresenta os valores de contração/retração obtidos em amostras de solo-cimento com $5 \%$ de cimento e os valores de contração obtidos em amostras de solo. Tanto o solo-cimento quanto o solo foram moldados nas duas condições de mistura (UH e UC) e ensaiados em câmara úmida com umidade relativa do ar controlada em $50 \%$. 


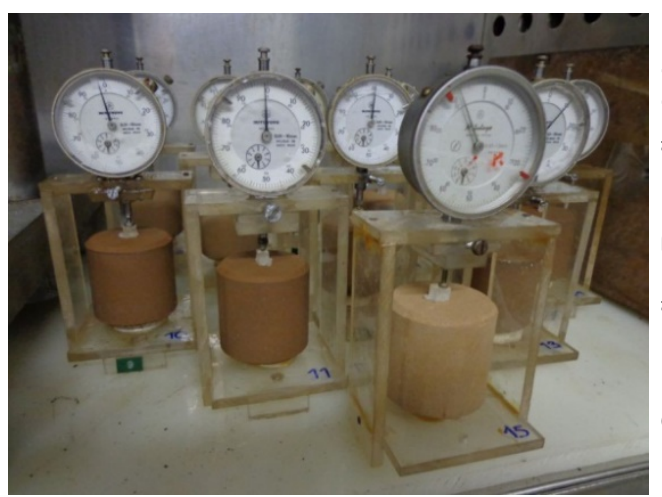

(a)

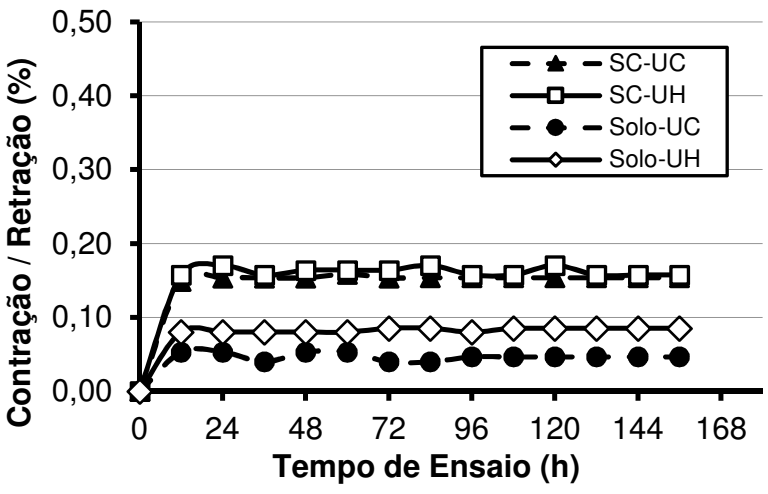

(b)

Figura 6: (a) Ilustração do ensaio de contração/retração e (b) Valores médios de contração/retração para as misturas de SC com 5\% de cimento e solo para duas condições de mistura (UH e UC)

A contração na amostra de solo na condição UC foi inferior à do solo na condição UH. As misturas de SC nas duas umidades de moldagem não apresentaram diferença significativa, embora maiores que as observadas no solo sem cimento. No comparativo das misturas de SC com as amostras de solo, observase que este último apresentou a metade do potencial de contração. Este resultado pode ser explicado pela alteração granulométrica e aumento da superfície específica da amostra com a adição do cimento e devido, adicionalmente, ao processo de hidratação do cimento que leva à retração. Os valores obtidos para as amostras são considerados baixos (inferiores a 0,50\%) e coerentes com a classe MCT (LA') do solo empregado na pesquisa (Villiboret al., 2009). Pitta (1985) propôs o uso de pesos a parâmetros que interferem no grau de severidade da retração e consequente fissuramento da camada de solo-cimento. Para avaliar o grau de severidade das fissuras são considerados: tipo de solo, tipo de composto da argila, granulometria inferior a $2 \mu \mathrm{m}$, tipo de cura da camada, desvio na umidade de compactação, densidade, teor e finura do cimento. 0 peso relativo de cada variável é somado de forma a compor o Índice de Retração, com classificação apresentada na Tabela 5. Para o solo e o cimento empregados nesta pesquisa foi totalizado peso de 27, indicando pequena possibilidade de retração danosa.

Tabela 5: Possibilidade de fissuração danosa conforme Pitta (1985)

\begin{tabular}{cc}
\hline Índice de Retração & Possibilidade de retração danosa \\
\hline$<22$ & MuitoPequena \\
23 a 27 & Pequena \\
28 a 32 & Normal \\
33 a 38 & Alta \\
$>38$ & Muito Alta \\
\hline
\end{tabular}

\section{TRECHO EXPERIMENTAL}

\subsection{Concepção e construção}

Em julho de 2009, através de uma parceria entre USP e DER-SP foi realizada a construção de um trecho experimental com uma das soluções em base de solo-cimento em um segmento de uma rodovia de pista simples em fase de implantação. 0 trecho experimental fica localizado em um segmento da vicinal (PTP10), denominada "Estrada do Leite", que interliga os municípios de Altinópolis e Batatais no interior do Estado de São Paulo. 0 tráfego previsto de projeto é de $\mathrm{N}=2,5 \times 10^{6}$ (AASHTO). 0 projeto estrutural de implantação desse pavimento foi realizado de acordo com o método do DNIT e contemplou como solução original uma base de solo-brita de $15 \mathrm{~cm}$ e um revestimento em concreto asfáltico de $4 \mathrm{~cm}$. Diferentes soluções ao projeto original foram construídas como trechos experimentais (Bernucci et al., 2010; Vasconcelos et al., 2011), sendo contemplado no presente artigo, o trecho com base de solo-cimento, conforme ilustrado na Tabela 6.

Tabela 6: Estruturas de projeto e trecho experimental com solo-cimento 


\begin{tabular}{ccccc}
\hline Camadas & Projeto & Espessura (cm) & TrechoExperimental & Espessura (cm) \\
\hline Revestimento & CBUQ & 4 & TSD AMP & 2,5 \\
Base & Solo-brita (40×60) & 15 & Solo-cimento (5\%) & 15 \\
Sub-base & Solo Jazida (E.I) & $2 \times 15$ & Solo Jazida (E.I) & $2 \times 15$ \\
Subleito & Solo Local (E.N) & - & Solo Local (E.N) & - \\
\hline
\end{tabular}

Para a construção da base foi adotada a Energia Intermediária, conforme recomendações técnicas (ET-DE-P00/004) do DER-SP e cimento do tipo CP II-Z, disponível na região. A mistura do solo-cimento foi processada em usina do tipo "pugmill". Após a compactação e imprimação com emulsão catiônica RR2C, o trecho foi mantido com desvio de tráfego por um período de 14 dias para a cura da camada, a fim de evitar danos estruturais. Na Tabela 7 são apresentados os valores do controle de compactação e RCS comparados com os dados de laboratório.

Tabela 7: Resumo dos dados de compactação obtidos para as amostras de obra e laboratório

\begin{tabular}{|c|c|c|c|c|c|c|c|c|c|}
\hline Condição & $\begin{array}{c}\text { Energia de } \\
\text { Compactação }\end{array}$ & $\begin{array}{l}\text { Idade } \\
\text { (dias) }\end{array}$ & $\begin{array}{c}\text { RCS } \\
\text { (MPa) }\end{array}$ & $\begin{array}{l}\text { C.V } \\
\text { (\%) }\end{array}$ & $\begin{array}{c}\gamma s m a x \\
\left(k N / m^{3}\right)\end{array}$ & $\begin{array}{l}\text { ysCampo } \\
\left(\mathrm{kN} / \mathrm{m}^{3}\right)\end{array}$ & $\begin{array}{c}h \\
(\%)\end{array}$ & $\begin{array}{l}\text { GC } \\
(\%)\end{array}$ & $\begin{array}{c}\text { Fator } \\
\text { a/c }\end{array}$ \\
\hline \multirow{2}{*}{ Lab. - UH } & \multirow{2}{*}{ Normal } & 7 & 2,90 & 4,4 & \multirow{2}{*}{19,5} & 19,68 & 10,4 & 100,8 & 2,1 \\
\hline & & 28 & 3,48 & 0,8 & & 19,56 & 10,9 & 100,2 & 2,2 \\
\hline \multirow{2}{*}{ Lab. - UC } & \multirow{2}{*}{ Normal } & 7 & 2,29 & 8,2 & \multirow{2}{*}{19,9} & 20,05 & 10,8 & 100,8 & 2,2 \\
\hline & & 28 & 3,05 & 3,5 & & 19,91 & 10,9 & 100,1 & 2,2 \\
\hline \multirow{2}{*}{ Obra - UC } & \multirow{2}{*}{ Intermediária } & 7 & 2,30 & 4,3 & \multirow{2}{*}{20,2} & 20,20 & 9,7 & 100,0 & 1,9 \\
\hline & & 28 & 4,95 & 7,1 & & 20,30 & 9,3 & 100,5 & 1,9 \\
\hline
\end{tabular}

\subsection{Monitoramento}

Após a construção, graças a um convênio de pesquisa entre USP e PETROBRAS, foram realizadas avaliações estruturais com a obtenção das bacias deflectométricas com a utilização da Viga Benkelman para os períodos pós-execução de T=0M, T=12M e T=24M e Falling WeightDeflectometer, FWD, para os períodos de $\mathrm{T}=21 \mathrm{M}$ e $\mathrm{T}=33 \mathrm{M}$, sendo "M" o número de meses a partir da abertura ao tráfego. Os levantamentos foram realizados entre os meses de maio e setembro de cada ano, caracterizado como período de estiagem no Estado de São Paulo, corroborando com os baixos valores de deflexão verificados. A Figura 7 apresenta os valores de deflexão máxima média para os levantamentos com a Viga Benkelman, além da bacia característica média para os levantamentos com o FWD. Para o processo de retroanálise apresentado a seguir foram utilizados apenas os dados de FWD.

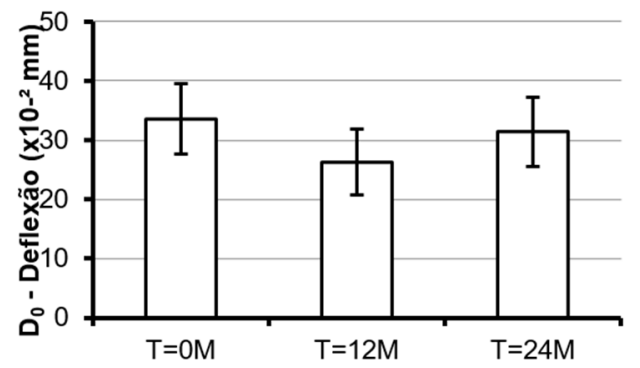

(a)

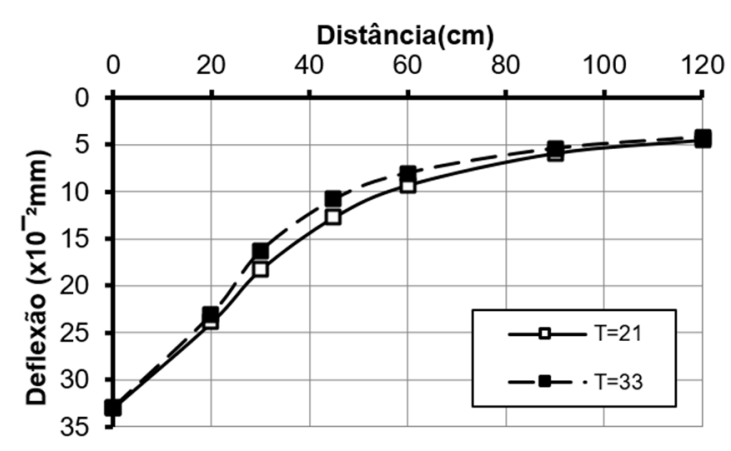

(b)

Figura 7: Resumo das deflexões obtidas: a) $D_{0}$ com Viga Benkelman e b) Bacia com FWD 


\subsection{Retroanálise}

Foram realizadas retroanálises com os dados das bacias deflectométricas obtidas por meio do equipamento FWD. Foram realizadas medidas no eixo da faixa de rolamento, relativas ao levantamento de $\mathrm{T}=$ $21 \mathrm{M}$, e nas trilhas internas e externas da faixa de rolamento, alternadamente ao longo do estaqueamento, para o levantamento de $\mathrm{T}=33 \mathrm{M}$, sendo o primeiro realizado no eixo (posição não usual) por limitação de tempo para levantamento dos dados com o FWD, bem como por se assumir ainda um estado íntegro da estrutura de pavimento.Os valores de deflexão foram normalizados para um único valor de carregamento, tendo como referência um semi-eixo padrão de $4.100 \mathrm{kgf}(40 \mathrm{kN})$. Os dados de partida para os valores de módulo de resiliência dos materiais foram empregados tendo como referência ensaios realizados em laboratório. Os coeficientes de Poisson empregados estão de acordo com as faixas recomendadas na IP-DE-P00/001 do DER/SP e também nos valores citados por Balbo (2007).

Para verificar a amplitude das possíveis combinações modulares, foram retroanalisadas: (i) a bacia média, (ii) a bacia média $+1 \sigma$ (somada um desvio padrão) e (iii) a bacia média - $1 \sigma$ (subtraída um desvio padrão), conforme mostrado na Tabela 8 . 0 revestimento em TSD não foi considerado como camada estrutural, portanto não há um valor de MR atribuído para o mesmo.

Tabela 8: Resumo da retroanálise do trecho experimental

\begin{tabular}{llllllll}
\hline \multirow{2}{*}{ Tempo } & Camadas & \multirow{2}{*}{ Material } & \multicolumn{2}{l}{ MR $(\mathrm{MPa})$} & \multirow{2}{*}{ Poisson } & \multirow{2}{*}{$\mathrm{h}(\mathrm{cm})$} \\
\cline { 5 - 7 } & & & Média & Media $+1 \sigma$ & Media $-1 \sigma$ & & \\
\hline \multirow{4}{*}{$\mathrm{T}=21 \mathrm{M}$} & Revest. & TSD & - & - & - & - & 2,0 \\
& Base & SC & 1.876 & 1.489 & 2.549 & 0,30 & 15,0 \\
& Reforço & Solo E.I & 245 & 245 & 245 & 0,40 & 15,0 \\
& Reforço & Solo E.I & 240 & 219 & 240 & 0,40 & 15,0 \\
& Subleito & Solo E.N & 219 & 209 & 235 & 0,45 & $\infty$ \\
\hline \multirow{2}{*}{ T=33M } & Revest. & TSD & - & - & - & - & 2,0 \\
& Base & SC & 1.530 & 1.275 & 1.703 & 0,30 & 15,0 \\
& Reforço & Solo E.I & 275 & 260 & 280 & 0,40 & 15,0 \\
& Reforço & Solo E.I & 255 & 229 & 260 & 0,40 & 15,0 \\
& Subleito & Solo E.N & 224 & 219 & 240 & 0,45 & $\infty$ \\
\hline
\end{tabular}

Houve pouca variação do MR na base de solo-cimento nos dois levantamentos ( $\mathrm{T}=21 \mathrm{M}$ e $\mathrm{T}=33 \mathrm{M}$ ). Porém, observa-se uma discreta redução dos módulos de resiliência do segundo levantamento, realizado com um pouco menos de 3 anos do trecho aberto ao tráfego, em relação ao primeiro levantamento, feito um ano antes. Essa diferença pode ser considerada um indicativo de microfissuração da camada de base cimentada. Apesar de não ser apresentado nesse artigo dados de monitoramento de estrutura de pavimento sem adição de cimento, é importante mencionar a mudança de comportamento estrutural entre pavimentos flexíveis e pavimentos semirrígidos, sendo o processo de dano entre ambos consideravelmente diferente, conforme abordado em trabalhos anteriores (Andrade et al., 2015).

\section{DISCUSSÃO DOS RESULTADOS}

As análises do efeito do tempo de cura e da umidade inicial do solo nas propriedades mecânicas após os ensaios de compactação, RCS, RTD e MR são apresentados a seguir.

\subsection{Efeito do Período de Cura nas Propriedades Mecânicas}

Foram observados ganhos de rigidez com o período de cura para os três ensaios analisados (MR, RCS e RTCD) e nas duas condições de umidade inicial do solo na mistura. Para os ensaios de RCS e RTCD, os maiores ganhos de resistências foram verificados nos primeiros 7 dias de cura, em que foram atingidos valores de $70 \%$ da resistência aos 28 dias. Para o ensaio de MR, a rigidez aos 7 dias atingiu $80 \%$ da rigidez aos 28 dias. Essa pequena variação pode decorrer da diferente forma de carregamento no ensaio de MR, na qual o material é solicitado por baixas cargas cíclicas, sendo um ensaio não destrutivo. 


\subsection{Efeito da Umidade Inicial do Solo nas Propriedades Mecânicas}

As amostras moldadas com o solo na condição UC apresentaram maiores valores de peso específico seco máximo ( $\gamma$ smax) no ensaio de compactação, comportamento semelhante verificado na mistura de solocimento. Este comportamento pode ser associado com o processo de secagem, podendo haver alteração da água de constituição, ou da camada dupla, nos solos naturais. De acordo com Terzaghi (1948), a água próxima da partícula de solo comporta-se como um sólido; no meio, como um líquido viscoso; e na superfície, como um líquido newtoniano. Para Saarenketo (1998), a água no solo pode ser classificada de três formas: (i) água adsorvida, também denominada água higroscópica, (ii) água viscosa, ou água capilar e (iii) água gravitacional, ou água livre. A pré-secagem de laboratório pode alterar a adsorvida e a viscosa. Após reumidificação, os argilo-minerais não readsorvem a água como naturalmente era constituída.

Os maiores valores de RCS na amostra de solo são verificados no ramo seco da curva de Proctor. Esse fato é atribuído à maior tensão de sucção e ao maior atrito entre as partículas de solo no ramo seco e, menor tensão de sucção e menor atrito no ramo úmido, resultando em um efeito de lubrificação da água neste ramo (Pinto, 2006). Por meio do cálculo do grau de saturação do solo (S\%), é possível verificar que o solo compactado na condição UC apresenta grau de saturação próximo de 75\%, enquanto que o solo compactado na condição UH atinge grau de saturação de 70\%, ambos verificados nas proximidades da umidade ótima. Pode-se inferir, dessa forma, que o solo compactado a partir da condição UC apresenta maior eficiência de densificação. Verificou-se também que os maiores valores de resistência encontramse no ramo seco da curva, para as duas condições de umidade de mistura testadas.

As amostras de solo-cimento apresentaram comportamento semelhante, com pico de resistência verificado no ramo seco da curva de Proctor. Resultado semelhante foi obtido por Carraro (1997) para uma mistura de solo-cal-cinza volante. Como ocorrem reações químicas e físicas entre as partículas de solo e a pasta de cimento, não é possível determinar com precisão a massa específica real dos grãos, tampouco a ponderação das densidades do solo e cimento que não representam o material resultante da mistura, inviabilizando o cálculo do grau de saturação. 0 valor máximo de RCS foi atingido com umidade entre 1,0 e 1,5\% abaixo da umidade ótima para as duas condições de umidade de mistura (UH e UC). Os resultados do peso específico seco e da RCS obtidos para uma amostra por ponto de umidade ensaiado são apresentados na Figura 8.

Dentre os fatores responsáveis pela variação da umidade correspondente à RCS máxima para as misturas de solo-cimento, tem-se o fator água cimento (a/c) como um dos principais. Esse parâmetro pode afetar de forma significativa o ganho de resistência em concretos. Quanto maior o valor desta razão, menores os valores de resistência. Em um estudo laboratorial de uma mistura de solo-cimento-bentonitaaplicada na construção de barreiras verticais, verificou-se que a variação no fator a/c afetou diretamente a resistência à compressão (Azambuja, 2004).

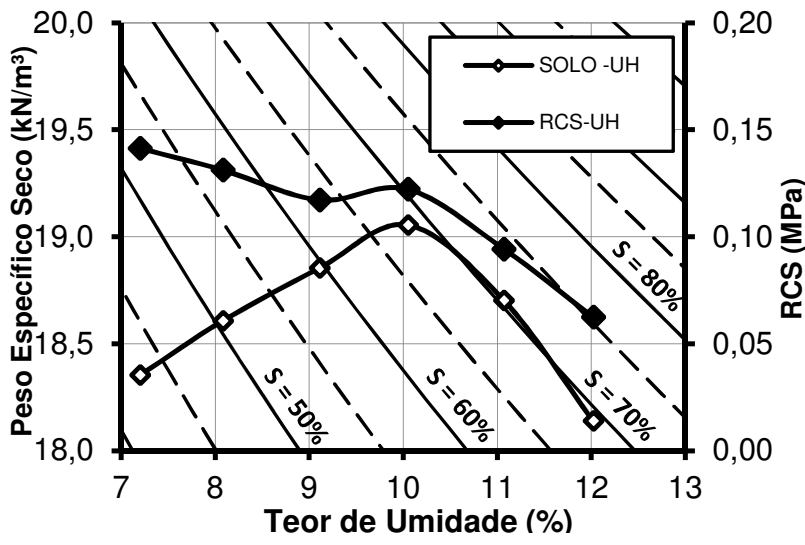

(a)

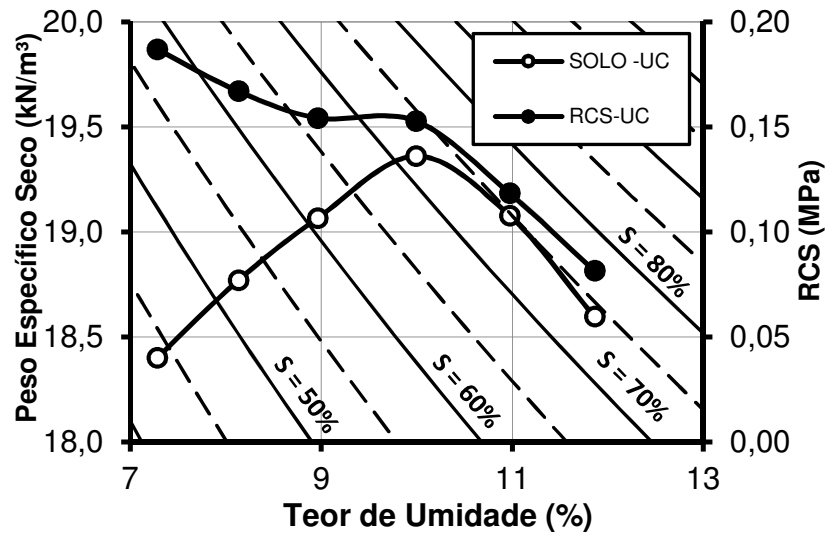

(b) 


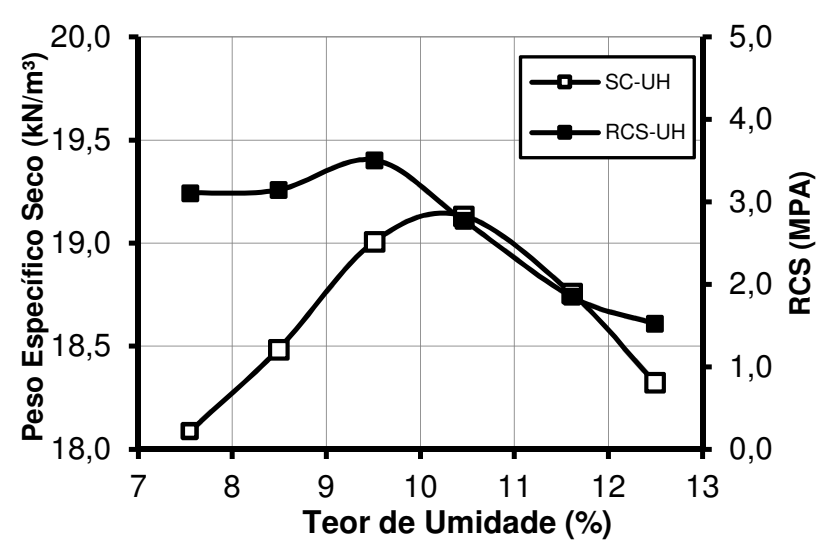

(c)

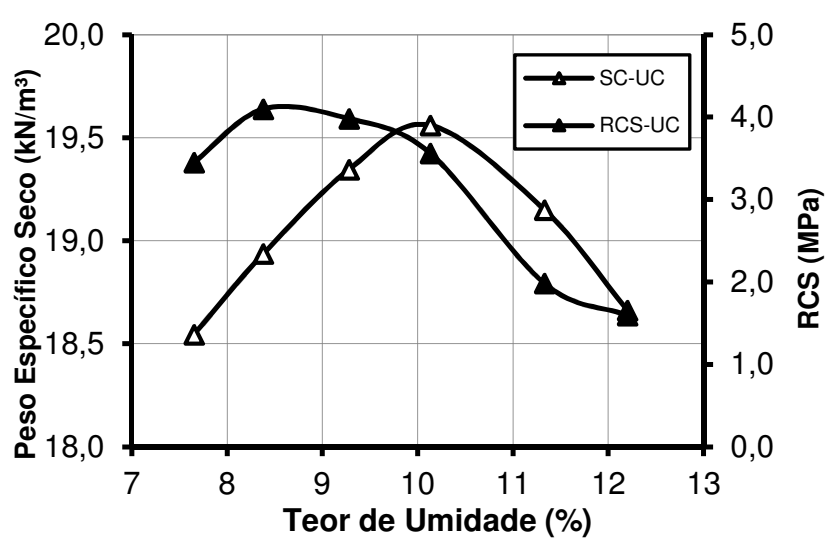

(d)

Figura 8: Curvas de compactação $\times$ RCS para amostra de: (a) solo na condição UH, (b) solo na condição UC, (c) solocimento na condição UH e (d) solo-cimento na condição UC

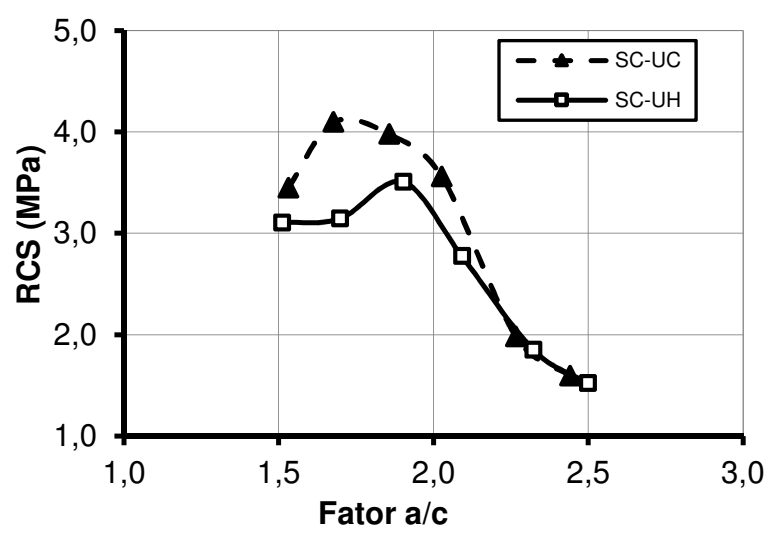

Figura 9: Fator a/c (água/cimento) obtidos da curva de compactação para as duas condições de mistura do solo-cimento (UH e UC)

A Figura 9 apresenta a combinação dos valores de RCS com seu respectivo fator a/c para as duas condições de mistura. Verifica-se que a RCS atinge um pico e a partir deste ponto, com o incremento do fator a/c, a resistência diminui de forma acentuada. A análise deve ser realizada de forma cuidadosa, pois ao mesmo tempo em que ocorre variação do fator a/c também ocorre a variação do peso específico aparente da mistura.

\subsection{Rigidez do solo-cimento em campo e em laboratório}

As amostras ensaiadas em laboratório apresentaram valores de rigidez compatíveis com os estudados por Ceratti (1991). Os resultados de campo obtidos por retroanálise foram inferiores, com valores entre 20 a 30\% do módulo de resiliência verificado em laboratório (UC) para os tempos de 21 e 33 meses de abertura ao tráfego, respectivamente. Esta redução significativa pode estar associada ao início do processo de microfissuração da base de solo-cimento. Caso a base se comportasse como uma camada homogênea e isotrópica, valores de módulo resiliente compatíveis com o de laboratório seriam também verificados em campo. No estudo de Bernucci (1995) em solos lateríticos, o módulo de resiliência equivalente obtido por retroanálise foi aproximadamente metade do valor de laboratório, sendo justificado pela existência de trincas de contração decorrentes da secagem. Pode-se ainda mencionar possíveis falhas durante o processo construtivo, além da diferença na forma como a umidade é controlada em campo (UC) e em laboratório (UH). 


\section{CONCLUSÕES}

Verificou-se neste estudo o efeito na umidade inicial da mistura de moldagem e do tempo de cura no comportamento mecânico de uma mistura de solo-cimento (composta por um solo laterítico e cimento do tipo CP-II E-32). Diante dos resultadosobtidos e apresentados, concluiu-se:

- processo de mistura do solo-cimento com variação na umidade de moldagem (UC - umidade de campo do solo in natura versus UH - umidade higroscópica do solo seco em laboratório) evidenciou uma pequena diferença referente a trabalhabilidade, melhorada na condição UC pela floculação, resultando em maiores valores de peso específico aparente seco (tendência contrária a observada por Pinto, 2006).

- a cura das misturas de solo-cimento levou ao aumento de todos os parâmetros mecânicos avaliados (RCS, RTCD e MR) para as duas condições de umidade inicial. Aos 7 dias de cura, foram obtidos entre 70 a $80 \%$ dos valores verificados aos 28 dias de cura.

- observou-se influência da umidade inicial de moldagem no comportamento mecânico (resistência à ruptura e rigidez) das misturas de solo-cimento. A tendência foi de maiores valores de MR e RCS (ensaios axiais) para os corpos de prova moldados com a mistura de cimento e solo a partir da umidade higroscópica (UH) e de maiores valores de RTCD (ensaio diametral) para mistura de cimento e solo a partir da umidade de campo (UC). Tal fato sugere que pode haver um efeito conjunto na resposta mecânica da umidade de moldagem e da direção de compactação e ensaio das amostras, devido à anisotropia do material. Cabe salientar ainda que os valores de peso específico seco máximo também foram distintos para um mesmo valor de umidade.

- a contração foi inferior para o solo na condição UC, mas não houve distinção na condição de umidade inicial para a mistura de solo-cimento. Os valores obtidos são considerados baixos e levam a consideração de pouco risco de deterioração do solo-cimento. A retração do solo-cimento é praticamente duas vezes a contração do solo sem cimento.

- fator água/cimento afeta de maneira significativa os valores de resistência da mistura de solocimento. Quanto maior o fator a/c, menor a resistência da mistura. Deve-se, porém, levar também em consideração o fato do índice de vazios ser diferente em cada ponto de umidade ensaiado.

- os valores de módulo de resiliência obtidos em laboratório não corresponderam aos valores obtidos em campo pela retroanálise. Os valores obtidos em campo são cerca de 3 a 4 vezes menores que os obtidos em laboratório. Atribui-se a diferença ao início do processo de microfissuração da base cimentada, possível falha construtiva, além da diferença na forma de ajuste da umidade em campo e em laboratório.

- conclui-se que o processo de secagem convencional afeta a densificação e comportamento mecânico do solo-cimento. É importante empregar em laboratório o solo na umidade de jazida e não seco antes da preparação das amostras para os ensaios. Os resultados e conclusões apresentados limitam-se ao tipo de solo (MCT: LA', AASHTO A-2-4) e teores de cimento empregados nos experimentos.

\section{REFERÊNCIAS}

ABNT (1986) NBR 7182 -Solo - ensaio de compactação. Associação Brasileira de Normas Técnicas, Rio de Janeiro.

ABNT (2011) NBR 7222 -Concreto e argamassa - Determinação da resistência à tração por compressão diametral de corpos de prova cilíndricos. Associação Brasileira de Normas Técnicas, Rio de Janeiro.

ABNT (2012a) NBR 12253 - Solo-cimento - dosagem para emprego como camada de pavimento. Associação Brasileira de Normas Técnicas. Rio de Janeiro.

ABNT (2012b) NBR 12023 - Solo-cimento - ensaio de compactação. Associação Brasileira de Normas Técnicas, Rio de Janeiro.

ABNT (2012c) NBR 12025 - Solo-cimento - ensaio de compressão simples de corpos de prova cilíndricos. Associação Brasileira de Normas Técnicas, Rio de Janeiro.

ASTM (2011) ASTM D558 - Standard Test Methods for Moisture-Density (Unit Weight) RelationsofSoil-CementMixtures. American Society for Testing and Materials, West Conshohocken. 
ASTM (2012) ASTM D698 - Standard Test Methods for Laboratory Compaction Characteristics of Soil Using Standard Effort. American Society for Testing and Materials, West Conshohocken.

ASTM (2007) D1633 - Standard test methods for compressive strength of molded soil-cement cylinders. American Society for TestingandMaterials, West Conshohocken.

Almeida, R. M. S. (2009) Estabilização de areias monogranulares para fins rodoviários - Estudo aplicado à região de Mira. Universidade de Aveiro - Dissertação de mestrado, Aveiro, Portugal.

Andrade, L.; Kuchiishi, A. K.; Bessa, I. S.; Vasconcelos, K. L.; Bernucci, L. L.B.; Beja, I. A.; Chaves, J. M. (2015) Comportamento Mecânico de Camadas de Bases Granular e Tratada com Cimento em Rodovia de Tráfego Muito Pesado In: XXIX Congresso de Pesquisa e Ensino em Transportes (ANPET), Ouro Preto.

AUSTSTAB (2012) Cement stabilization practice. Technical note, №5. AustralianStabilizationofIndustryAssociation. Australian.

Balbo, J. T.(2007) Pavimentação Asfáltica: materiais, projeto e restauração. (1ํaed.). Oficina de Textos, São Paulo.

Bechara, M.F. A.P., Furlan A.C. Gigante e G.T.P. Fabbri (2010) Propriedades mecânicas de misturas de solo-cimento com solo laterítico e solo não laterítico. 24ํㅡㄹ Congresso de Pesquisa e Ensino em Transportes - 24ํo ANPET, Salvador, p. 1-12.

Bernucci, L. L. B. (1995). Considerações sobre o dimensionamento de pavimentos utilizando solos lateríticos para rodovias de baixo volume de trafego. Tese de Doutorado, Escola Politécnica, Universidade de São Paulo, São Paulo.

Bernucci, L. B., Vasconcelos, K. L., Sanbonsuge, K., Rufo, R. C., Castro Neto, A.M. de, Nascimento, L.A.H. (2010) Estudo Comparativo de Bases de Pavimentos por meio de Trechos Monitorados: Efeito da Adição de Cimento In: 40a Reunião Anual de Pavimentação (ABPv), Rio de Janeiro.

Carraro. J. A. H.(1997) Utilização de resíduos industriais na estabilização de um solo residual de arenito. Dissertação de mestrado. Universidade Federal do Rio Grande do Sul. Escola de Engenharia. Programa de Pós-Graduação em Engenharia Civil. Porto Alegre.

Ceratti. J. A. P. (1991) Estudo do comportamento à fadiga de solos estabilizados com cimento para utilização em pavimentos. Tese de Doutorado. Universidade Federal do Rio de Janeiro, Rio de Janeiro.

DNIT (2006) Manual de pavimentação. Departamento Nacional de Infra-Estrutura de Transportes. Rio de Janeiro.

DNIT (2010)134/2010-ME: Pavimentação - Solos - Determinação do módulo de resiliência. Departamento Nacional de InfraEstrutura de Transportes. Rio de Janeiro.

Guthrie, W.S.; J.E. Michener; B.T. Wilson e D L. Eggett (2009) Effects of environmental factors on construction of soil-cement pavement layers. Journal of the Transportation Research Board. Washington, v. 2104, p. 71-79. DOI: 10.3141/2104-08

Luz, M.P. e A.B.Parreira (2003) Estudo da influência da umidade pós-compactação no índice de suporte CBR de solos do subleito de rodovias do interior de São Paulo. 34ํㅡ Reunião Anual de Pavimentação, ABPV, Campinas, p. 153-167.

Nogami, J.S.; D.F.Villibor; A.Z. Neto e P.M. Serra (1990) Comportamento de dois trechos experimentais de solo-cimento construídos pelo DER-SP. ABPV, Anais da 24르 Reunião Anual de Pavimentação, Belém.

Nogami, J. S e D. F. Villibor (1995) Pavimentação de baixo custo com solos lateríticos. Villibor. São Paulo, SP, p.240.

Massad, F. (2003) Obras de Terra: curso básico de Geotecnia.(2ae ed.).Oficina de Textos, São Paulo, SP.

Mitchell, J. K. e El Jack, S.A. (1966) The Fabric of Soil-Cement and Its Formation. Clays and Clay Minerals; v.. 14; no. 1; p. $297-$ 305; DOI: 10.1346/CCMN.1966.0140126.

Parente, E. B.; A. B. Parreira e J.B.Soares (2002) Avaliação do comportamento mecânico de um solo laterítico e de outro não laterítico estabilizados com cimento. XVI ANPET - Congresso de Pesquisa e Ensino em Transportes, Panorama Nacional de Pesquisa em Transportes, p. 95-107.

Pinilla, J.D, Miller, G.A., Cerato, A.B. e D.S. Snethen (2011) Influence of Curing Time on the Resilient Modulus of Chemically Stabilized Soils. Geotechnical Testing Journal. v. 34, No. 4, p. 364-372. DOI: 10.1520/GTJ103369.

Pinto, C. S. (2006) Curso Básico de Mecânica dos Solos em 16 Aulas (3ạ. ed.).Oficina de Textos, São Paulo, SP.

Saarenketo, T. (1998) Electrical properties of water in clay and silty soils. Journal of Applied Geophysics, v. 40, No. 1-3, p. 73-88; DOI: 10.1016/S0926-9851(98)00017-2.

Pitta, M.R (1985) Retração de solo-cimento. ABCP, São Paulo, SP

Terzaghi, K. (1948) Soil mechanics in engineering practice.(3th. ed). John Willey \& Sons, Inc,New York, United States.

Vasconcelos, K. L., Sanbonsuge, K., Bernucci, L. B., Rufo, R. C., Nascimento, L.A.H., Castro Neto, A.M. de (2011) Estudo Laboratorial e de Campo de Revestimentos Asfálticos Preparados com Ligantes de Diferente Consistência In: 17a Reunião de Pavimentação Urbana, Porto Alegre.

Vendruscolo, M. A. (1996) Análise numérica e experimental do comportamento de fundações superficiais assente em solo melhorado. Dissertação de mestrado, Universidade Federal do Rio Grande do Sul. Programa de Ppos-Graduação em Engenharia Civil, p.163. Porto Alegre.

Villibor, D. F., J.S. Nogami, J.R. Cincerre, P.R.M. Serra e A.Z. Neto (2009) Pavimentos de baixo custo para vias urbanas (2ª. Ed.) Arte\&Ciência, São Paulo, SP. p. 45-60.

Yoon, S.e M. A. Farsakh (2009) Laboratory investigation on the strength characteristics of cement-sand as base material. Journal of Civil Engineering, Korean Society of Civil Engineers, v.13, p.15-22. DOI: 10.1007/s12205-009-0015-x. 